\title{
Surgical Treatment of Intrarticular Calcaneal Fractures.
}

\author{
Dr. D.Karthick ${ }^{1}$, Dr. J.K. Giriraj Harshavardhan ${ }^{2}$ Dr. Ganesan Ganesan Ram ${ }^{3}$, \\ Dr.P.V.Vijayaraghavan ${ }^{4}$ \\ ${ }^{1,3,4}$ (Department Of Orthopaedics, Sri Ramachandra Medical College /Sri Ramachandra University, India) \\ ${ }^{2}$ Associate professor of orthopedics Sri ramachandra university \\ Corresponding author : Dr. J.K. GIRIRAJ HARSHAVARDHAN
}

\begin{abstract}
Abstrac: $75 \%$ of calcaneal fractures are intra articular. Treating calcaneal fractures is a challenge for orthopaedic surgeon due to the complex fracture pathology. A wide range of treatment options varying from non operative to operative methods are available. The purpose of this study is to assess the functional outcome of surgically treated intrarticular calcaneal fractures along with certain important tips and observations made during this case study.
\end{abstract}

Keywords: calcaneum, intrarticular, plating, modified rowe scale,screw fixation.

\section{I. introduction}

Descriptions of calcaneal fractures exist since 1839 when compression/axial loading mechanism causing this type of fracture has been described [1]. In 1843 Malgaigne described this fracture and proposed a classification .The treatment of these fractures has been evolved since then from conservative to surgical approach .The initial publications of surgical treatment of calcaneal fracture were by Leriche .. Treatment options ranges from non operative to operative methods $4,{ }^{13}$

\section{Materials And Methods}

There were 8 intrarticular calcaneal fractures in 7 patients, with a minimum follow up of 3 months. Mean age of the patient was 33 years among which 6 patients were male and 1 female. 1 patient had a bilateral calcaneal fracture. Mechanism of injury was fall from height in all patients. None of the patients had associated vertebra fractures or neurological deficit. Patients were evaluated clinically and radiologically, lateral radiographs of calcaneum were taken. Intrarticular fractures were classified based on the Essex Lopresti classification and computerized tomography imaging with $3 \mathrm{~d}$ reconstruction was taken. All patients had swelling associated with the fracture which did not allow immediate surgery. A posterior back slab was given for all patients. Ice compresses were given over the lateral aspect of hindfoot after removal of plaster slab every 3 to 4 hours. Crushed ice or cubes were placed in a plastic cover and the cover was tied. The plastic bag with ice was placed over the hindfoot for a period of 15 minutes. Limb was strictly elevated with 2 pillows. After all these measures, usually swelling reduced within a period of 7 to 10 days. Only on observance of wrinkles over the planned operative site (refer fig.5.1) was surgery done.

All cases were exposed by extensile lateral approach. Full thickness flaps were made using the "no touch' technique making sure that sural nerve and peroneal tendons were not incised. The flaps were retracted and held with $\mathrm{K}$ wires. The fracture was reduced - tuberosity fragment was valgized, the anterior fragement was reduced and the joint depression was elevated and removing the lateral wall. The reduction was checked under image intensifier (for restoration of Bohler's and Gissane angle) and was stabilized with either reconstruction plates or calcaneum locking plates after replacing the lateral wall. In some cases 2 reconstruction plates ( 1 plate to support the subchondral bone and another plate to stabilize the main fragements ) were used along the lateral aspect. The wound was closed by Algower Donati suturing technique.

Post operatively limb elevation was maintained for 72 hours. Compressive bandage was applied over sterile dressing. Complete suture removal was done at an average of 18 days. All operated patients were kept on absolute non weight bearing for 6 weeks followed by touchdown weight bearing with active and passive movements of ankle and sub talar joints. Full weight bearing was allowed from 12 weeks. Regular clinical follow up examination was performed monthly in all cases and functional outcome was assessed by using Modified Rowe scale (Table 3) after following the cases over a mean period of 4 months.

Case 1:

\section{Case Study}

A 22year old male had come with history of fall from height. Pre Operative Images. 

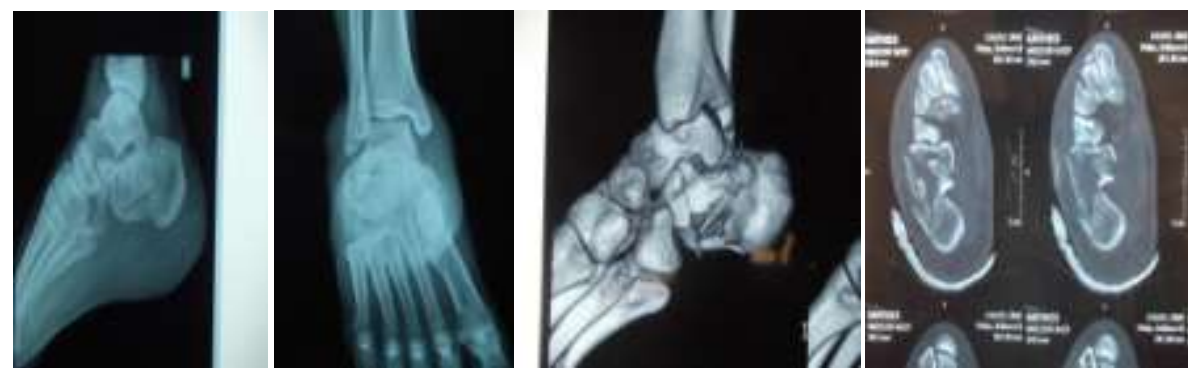

Post operative images:
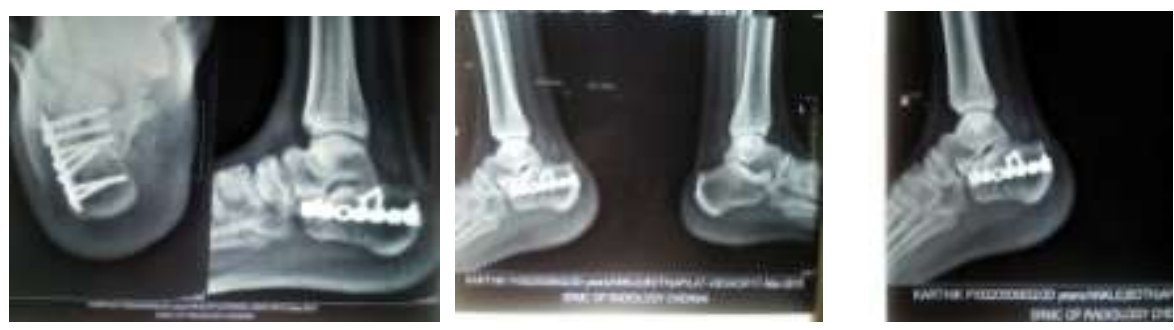

6weeks:
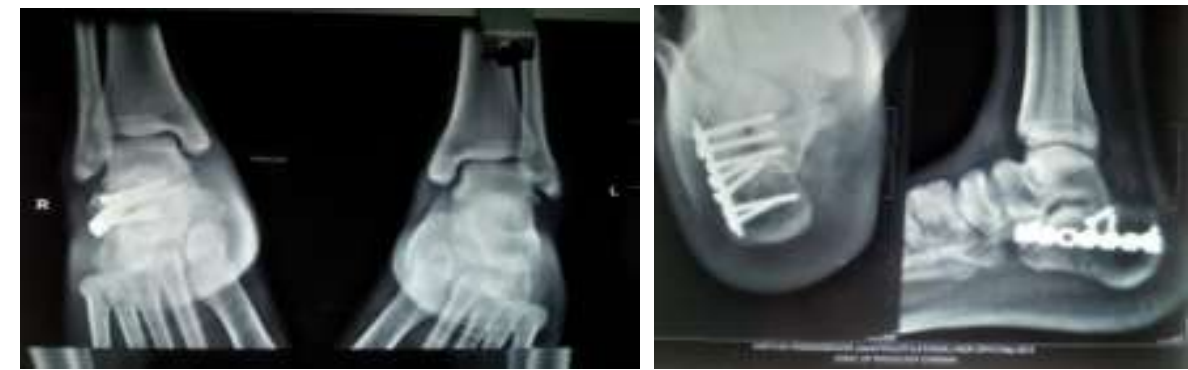

Months follow up:

6 months follow up :

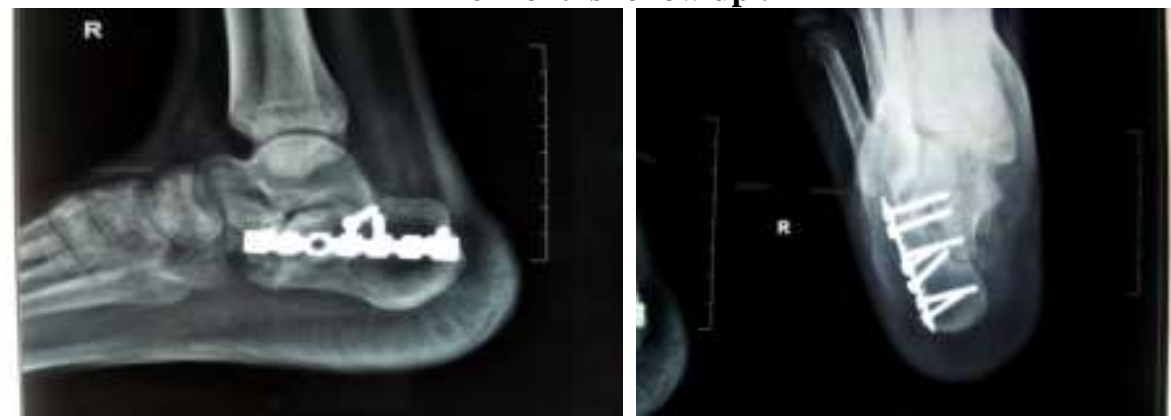

Case 2 : Ravindran

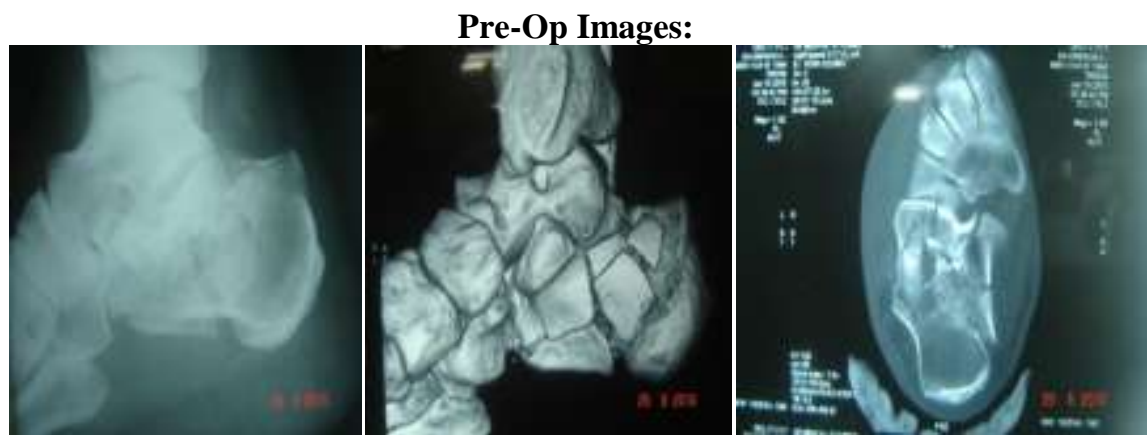

Intra Operative pics: 

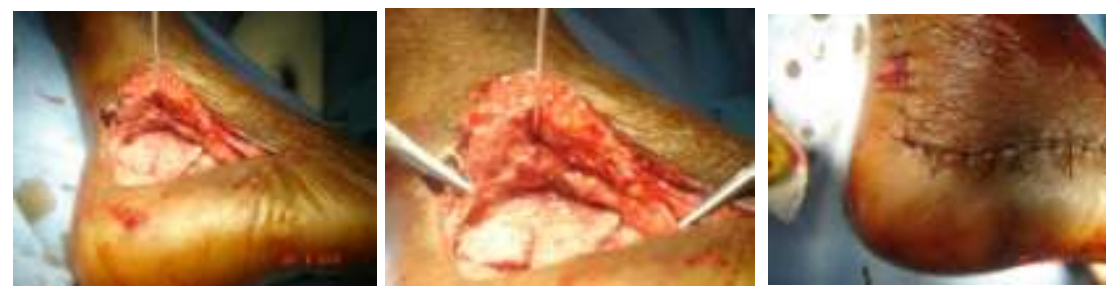

6 weeks post op :
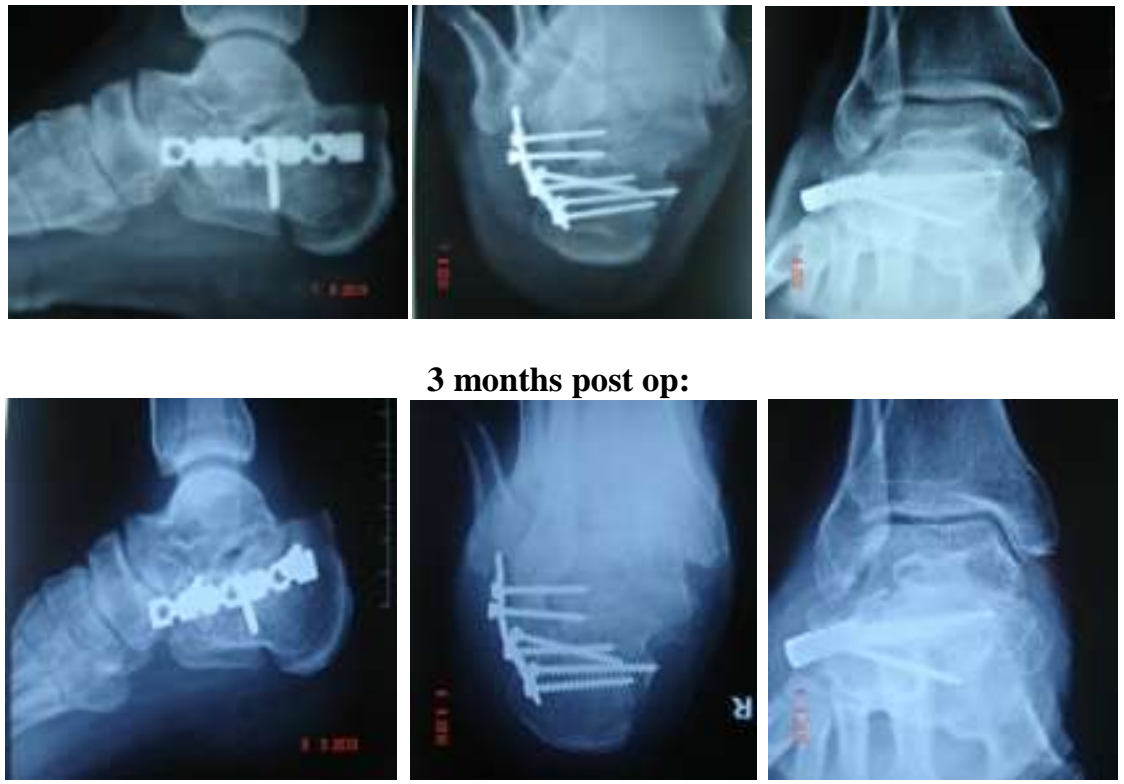

3 months post op:
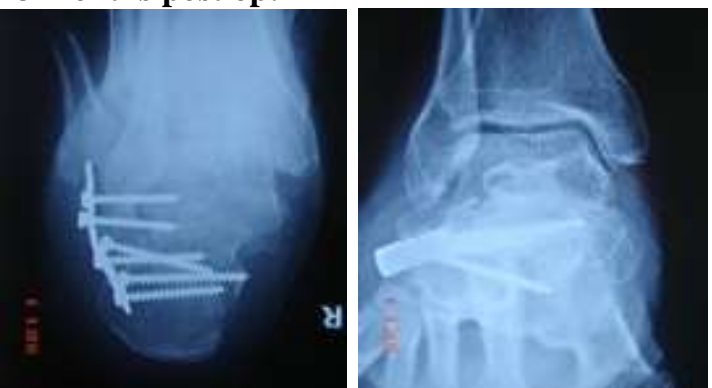

\section{Figures and Tables}

Patients Distribution as per functional outcome as per Modified Rowe score14: Modified Rowe score14: based upon stability, motion and function post operatively based on which scoring was done.

\section{Excellent $>85$}

- Good 70-85

- Satisfactory 55-70

- Poor $<55$

All 8 patients had a mean score of above 85 , hence proving surgical fixation as an effective method for intrarticular calcaneal fractures.

\section{Conclusion}

Calcaneum fractures account for $2 \%$ of all fractures, $60 \%$ of tarsal bone fractures. $10 \%$ of fractures are bilateral and $75 \%$ are intra articular1.10\% of fractures are associated with vertebrae fractures. Mechanism of injury in majority of patients is axial loading i.e. fall from height. Other mechanisms are brake pedal injuries and high velocity trauma. Current development in imaging technology has allowed better understanding of this complex fracture pathology. Sanders classification3 of intra articular Calcaneum fractures is widely used now a days because of its proven correlation with management and prognosis. Treating Calcaneum fractures is a challenge for orthopaedic surgeon.

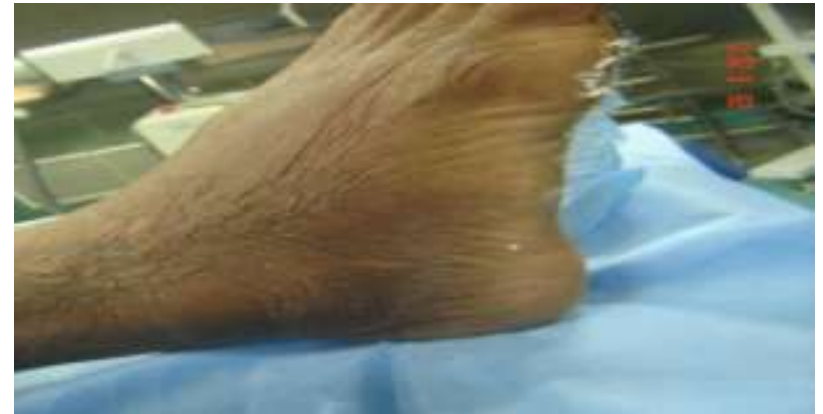

(fig 5.1) 
Proper pre- operative planning in treating calcaneal fractures helps in producing better results. It is important that the swelling in the foot must recede and presence of wrinkles over skin is a good sign as it reduces the chances of vascularity damage due to edema and prevents necrosis of the skin.

The following cases showed very good results following surgical treatment. Intra-operative planning and proper patient education and mobilization helped in obtaining excellent results and almost no interference in doing day to day life. Flap necrosis can be avoided by reducing swelling by limb elevation, splinting and ice compresses. Surgery should not be done in the presence of swelling. It may take 7 to 10 days for the swelling to subside and wrinkles to appear. Even though reduction becomes slightly more difficult due to the delay wound complications which are more devastating can be avoided.

\section{Acknowledgements}

I would like to thank Prof.P.V.Vijayraghavan and Dr.Giriraj Harshavardhan for their time and support in this study.

\section{References}

[1]. Fitzgibbons TC, McMullen ST, Mormino MA. Fractures and dislocations of the calcaneum. In: Bucholz RW and Heckman JD Eds. Rockwood and Green's Factures in adults, Vol.3, 5th ed. Philadelphia: Lippincott Williams \& Wilkins, 2001: 2133-2179.

[2]. Leung KS, Yuen KM, Chan WS. Operative treatment of displaced intra-articular fractures of the Calcaneum. J Bone Joint Surg (Br). 1993; 75:196-201

[3]. Sanders R, Fortin P, Diapasquale T, Walling A. Operative treatment in 120 displaced calcaneal fractures: results using a prognostic computed tomography scan classification. Clin Orthop. 1993; 290:295

[4]. Sanders R. Intra-articular fractures of the calcaneum: present state of the art. J Orthop Trauma. 1996; 6:252-265.

[5]. Crosby LA, Fitzgibbons TC. Open reduction and internal fixation of type II intra-articular calcaneum fractures. Foot Ankle Int. $1996 ; 17: 253-258$

[6]. Jarvholm U, Korner L, Thoren O, Wiklund LM. Fractures of the calcaneum: a comparison of open and closed treatment. Acta Orthop Scand 1984; 55:652-6

[7]. Pozo JL, Kirwan EOG, Jackson AM. The long-term results of conservative management of severely displaced fractures of the Calcaneum. J Bone Joint Surg. [Br] 1984; 66-B:386-90

[8]. Huang PJ, Huang HT, Chen TB. Open reduction and internal fixation of displaced intra-articular fractures of the Calcaneum. J Trauma. 2002;52946-951

[9]. Kitaoka HB, Schaap EJ, Chao EY, An KN. Displaced intra-articular fractures of the Calcaneum treated non- operatively. Clinical results and analysis of motion and ground-reaction and temporal forces. J Bone Joint Surg Am 1994; 76:1531-40.

[10]. Thordarson DB, Krieger LE. Operative vs. nonperative treatment of intra-articular fractures of the Calcaneum: a prospective randomized trial. Foot Ankle Int 1996; 17:2-9.

[11]. Chan S, Ip FK. Open reduction and internal fixation for displaced intra-articular fractures of the os calcis. Injury 1995;26:111-5.

[12]. Hutchinson F 3rd, Huebner MK. Treatment of os calcis fractures by open reduction and internal fixation. Foot Ankle Int 1994; 15:225-32.

[13]. Eastwood DM, Phipp L. Intra-articular fractures of the Calcaneum: why such controversy? Injury 1997;28:247-59.

[14]. Buckley RE, Meek RN. Comparison of open versus closed reduction of Intraarticular calcaneal fractures: a matched cohort in workmen. J Orthop Trauma. 1992;6:216-22.

[15]. Zeman P, Zeman J, Matejka J, Koudela K. Long-term results of calcaneal fracture treatment by open reduction and internal fixation using a calcaneal locking compression plate from an extended lateral approach. Acta Chir Orthop Traumatol Cech. 2008 Dec; 75(6):457-64.

[16]. Leung KS, Chan WS, Shen WY, Pak PPL, So W-S, Leung PC. Operative treatment of Intraarticular fracture of the os calcis; the role of rigid internal fixation and primary bone grafting : preliminary results. J Orthop Trauma. 1989; 3:232

[17]. Kevin A et al. Functional outcome measures after displaced intra-articular calcaneal fractures. J Bone Joint Surg Br. 1996; 78-B: 119- 23 .

[18]. Levine DS, Helfet DL. An introduction to the minimally invasive osteosynthesis of intra-articular calcaneal fractures. Injury. 2001 May; 32 Suppl 1:SA51-4.

[19]. Potter MQ, Nunley JA.Long-term functional outcomes after operative treatment for intra-articular fractures of the Calcaneum. J Bone Joint Surg Am. 2009 Aug; 91(8):1854-60. doi: 10.2106/ JBJS.H.01475.

[20]. O'Farrell DA, O'Byrne JM, McCabe J, Stephens MM. Fractures of the os calcis: improved results with internal fixation. Injury $1993 ; 24: 263-5$. 